DOI: https://doi.org/10.47405/mjssh.v5i5.406

\begin{tabular}{|c|c|}
\hline $2 \sqrt{10}$ & Malaysian Journal of Social Sciences and Humanities (MJSSH) \\
\hline $\begin{array}{l}\text { Malaysian Journal of } \\
\text { Socal scionces and }\end{array}$ & Volume 5, Issue 5, May 2020 \\
\hline (MJ-SSH) & e-ISSN : 2504-8562 \\
\hline & $\begin{array}{l}\text { Journal home page: } \\
\text { www.msocialsciences.com }\end{array}$ \\
\hline
\end{tabular}

\title{
Gaya Pembelajaran dan Persekitaran Sekolah serta Perkaitannya Dengan Kecerdasan Emosi Pelajar Sekolah Menengah Luar Bandar
}

\author{
Andang Andaiyani Binti Ahmad', Abdul Said Bin Ambotang1 \\ 1Fakulti Psikologi dan Pendidikan, Universiti Malaysia Sabah (UMS) \\ Correspondence: Andang Andaiyani Binti Ahmad (danish_danials720@yahoo.com)
}

\begin{abstract}
Abstrak
Kajian ini dilaksanakan untuk mengenal pasti hubungan gaya pembelajaran dan persekitaran sekolah dengan kecerdasan emosi pelajar sekolah menengah luar bandar. Kajian ini menggunakan kaedah kuantitatif dalam menentukan perhubungan antara kesemua pemboleh ubah tidak bersandar (gaya pembelajaran dan persekitaran sekolah) dengan pemboleh ubah bersandar (kecerdasan emosi). Sampel kajian ini telah diperoleh daripada pelajar sekolah menengah kebangsaan dalam daerah Tawau, Sabah. Sebanyak 351 sampel telah diperoleh oleh penyelidik untuk diuji dalam kajian ini. Setiap hipotesis telah diuji dengan menggunakan perisian Statistical Package for Social Sciences (SPSS) Versi 20.0. Dapatan kajian mendapati terdapat hubungan yang signifikan pada tahap sederhana kuat iaitu $r=0.431$ di antara pemboleh ubah gaya pembelajaran dengan kecerdasan emosi pelajar, hubungan yang signifikan pada tahap kuat $r=0.528$ di antara pemboleh ubah persekitaran sekolah dan kecerdasan emosi pelajar. Oleh hal yang demikian kajian ini turut mengesyorkan bahawa maklumat dan pengetahuan ibu bapa dan guru-guru adalah sangat penting dalam mengenalpasti keadaan kecerdasan emosi dan menggunakan kecerdasan emosi murid dalam membantu murid agar dapat mendepani carabaran masa hadapan yang kian mencabar.
\end{abstract}

Kata kunci: gaya pembelajaran, persekitaran sekolah, kecerdasan emosi

\section{The Relationship Between Learning Style and School Environment with Emotional Quotient of Secondry School Students in Outskirt Area in Tawau, Sabah}

\begin{abstract}
The study was conducted to see the relationships between the factors that effects emotional quotient. Quantitative methods were used to determine the relationships between all independent variables (learning style and school environment) and dependent variables (emotional quotient). The samples for this study were obtained from the secondary students in outskirt area of Tawau District. There were 351 samples which were collected for the purpose of this study. Statistical Package for Social Sciences (SPSS) version 20.0 software was used to test each hypothesis in this study. The finding of this study suggested that there is a significant and moderately strong relation, $r=0.431$ between the students' learning styles with the level of students' emotional quotient. There is also a strong relation between school environment with the level of students' emotional quotient at $r=0.528$. In this study also suggests that parents and teachers' information and knowledge are very impotant in identifying emotional intelligence and using pupil's emotional intelligence in helping students cope with challenging future challenges.
\end{abstract}


Keywords: learning style, school environment, emotional quotient

\section{Pengenalan}

Emosi berasal dari bahasa Greek iaitu emover yang membawa maksud 'untuk keluarga'. Emosi dapat dipamerkan oleh setiap individu dalam bentuk tindakan dengan tujuan untuk memenuhi kepuasan individu itu sendiri dan ia boleh dikatatakan sebagai satu keadaan di mana perasaan yang ditunjukkan pada proses fisiologi dan psikologi seseorang individu itu (Mahmood,1992). Mayer Cobb (2000) mendefinisikan kecerdasan emosi sebagai kebolehan memproses maklumat berkaitan emosi dan mentakrifkannya sebagai persepsi, sikap, memendam perasaan dan juga pengurusan emosi. Secara ringkasnya dapat disimpulkan kecerdasan emosi adalah satu set tindak balas automatik, viseral dan komunikasi emosi seperti ekspresi muka, perkataan, tingkah laku, dan isyarat yang dipamerkan oleh seseorang itu. Peter Salovey dan John Meyer adalah dua orang pakar yang memperkenalkan kecerdasan emosi (EQ) dalam tahun 1990. Selepas itu pada tahun 1995, Daniel Coleman pula mula menulis buku yang bertajuk 'Emotional Intelligence' yang mendedahkan kepentingan dan keperluan kecerdasan emosi (EQ) dalam kehidupan.

Gaya pembelajaran murid memainkan peranan penting dalam keberhasilan murid untuk setiap subjek yang dipelajari. Guru sepatutnya mengetahui gaya pembelajaran pelajar dan kecerdasan emosi murid agar dapat mencapai objektif pengajaran dan pembelajaran semasa dalam kelas. Pembelajaran tidak hanya berkaitan penambahan pengetahuan dan mengingat semula maklumat yang dipelajari, namun pembelajaran sepatutnya dapat membolehkan seseorang muird itu untuk menguasai konsep dan memahami maklumat sekali gus mampu mengaplikasikannya dalam kehidupan sebenar.

Persekitaran sekolah turut memainkan peranan yang penting dalam kemenjadian murid. Persekitaran sekolah yang kondusif amat baik untuk proses pengajaran dan pembelajaran berlaku. Persekitaran atau suasana sekolah yang tenang dan nyaman, sesuai untuk proses pengajaran dan pembelajaran. Keadaan ini dianggap sebagai sesebuah sekolah itu mempunyai persekitaran sekolah yang berkesan yang mampu membantu pelajar berasa tenang dalam proses pembelajaran. Abdul Rahman an-Nahlawi (1995) menyatakan bahawa persekitaran sekolah yang baik atau berkesan mampu mewujudkan integrasi dan keharmonian sesama pelajarnya yang berbeza status sosio-ekonomi mereka.

\section{Penyataan Masalah Kajian}

Dalam menghadapi cabaran zaman moden, pengetahuan asas mengenai pendidikan adalah sesuatu yang relevan dan perlu diperkukuhkan supaya perspektif baharu dalam menjana perubahan untuk pendidikan dapat dilakukan dengan berkesan. Namun keperluan dan budaya sekolah sangat dipengaruhi oleh kemajuan teknologi masa kini yang sentiasa berubah. Sesetengah sekolah terlalu ghairah untuk menjadi sebuah sekolah yang cemerlang justeru terlalu berorientasikan kepada akademik sehingga mengabaikan keperluan emosi murid. Dunn (1984) menyatakan bahawa kegagalan pelajar bukan disebabkan oleh kurikulum sebaliknya disebabkan oleh mereka tidak belajar mengikut gaya pembelajaran masing-masing. Clark-Thayer (1987) melaporkan bahawa gaya pembelajaran pelajar berbeza-beza. Oleh itu gaya pembelajaran pelajar perlu sepadan dengan kaedah pengajaran guru. Maka pelajar harus mengenal pasti gaya pembelajaran yang disukai dan sesuai agar pembelajaran berlaku dengan lebih berkesan Terdapat beberapa dapatan kajian yang membuktikan bahawa adalah penting untuk pelajar mengetahui gaya pembelajaran mereka untuk berjaya dalam pelajaran.

Menurut kajian yang telah dijalankan oleh Zainuddin dan Md. Saharudin (2009) di sebuah sekolah menengah menunjukkan bahawa kepelbagaian gaya pembelajaran dan tahap kemahiran belajar memberi kesan yang berbeza terhadap tabiat dan kesungguhan pembelajaran akademik pelajar. Menurut Ng Sook Chin (2005) kajian tentang gaya pembelajaran pelajar adalah perlu dan kajian seperti ini akan dapat mencelikkan guru dan pelajar mengenai gaya pembelajaran yang baik dan sesuai 
seterunya meningkatkan minat pelajar dalam sesuatu mata pelajaran dan membantu mereka dalam pembelajaran.

Persekitaran sekolah yang baik juga akan membantu pelajar untuk berjaya dan stabil dari segi emosi. Faktor iklim sekolah atau persekitaran sekolah membantu mewujudkan kestabilan emosi, terdapat beberapa pengkaji telah mengetengahkan beberapa ciri-ciri persekitaran sekolah yang baik. Menurut kajian yang telah dilakukan oleh Halpin dan Croft (1963) persekitaran sekolah yang baik untuk pelajar adalah apabila pelajar merasa selamat dan belajar bersungguh-sungguh untuk kejayaan mereka dalam pelajaran. Kebanyakan kajian yang dijalankan tentang persekitaran sekolah menunjukkan bahawa persekitaran sekolah yang baik akan mewujudkan suasana pembelajaran bermotivasi dan positif seterusnya pelajar memperoleh pencapaian yang baik. Menurut kajian yang dijalankan oleh Ahmad Zabidi (2006) di sebuah sekolah menengah menunjukkan bahawa persekitaran sekolah yang berkesan terhasil apabila suasana sekolah aman, cantik, selamat dan cukup ruang untuk belajar. Ibrahim (1993) turut menegaskan bahawa persekitaran yang baik perlu wujud di sesebuah sekolah untuk keseimbangan pelajar dari segi jasmani, emosi, rohani, intelek dan sosial.

\section{Objektif Kajian}

Objektif khusus bagi kajian ini ialah:

i. Mengenal pasti hubungan antara gaya pembelajaran dengan kecerdasan emosi murid.

ii. Mengenal pasti hubungan antara persekitaran sekolah dengan kecerdasan emosi murid.

\section{Tinjauan Literatur}

\section{Konsep Gaya Pembelajaran}

Gaya pembelajaran membawa maksud kaedah ataupun cara. Maka gaya pembelajaran seseorang dapat didefinisikan sebagai kaedah pembelajaran yang bertindak dengan persekitarannya agar dapat memproses, mentafsir dan memperoleh maklumat, ilmu pengetahuan atau kemahiran yang diingini oleh seseorang. Menurut Hunt (1990) dalam Suresh Kesavalu (2005), gaya pembelajaran adalah tertakluk kepada syarat-syarat pendidikan yang membolehkan sesuatu pembelajaran berlaku dengan berkesan dan syarat syarat itu merangkumi persekitaran kawasan pembelajaran, struktur pembelajaran sama ada formal, informal serta gaya pembelajaran yang digemari yang mana gaya pembelajaran akan berubah mengikut suasana dan keadaan masing-masing.

Namun menurut Vermunt dan Van Rijswijk (1988), gaya pembelajaran sebagai serangkai aktiviti, orientasi belajar dan konsep pembelajaran, pendidikan dan kerjasama yang menjadi ciri penting pelajar tertentu pada masa tertentu. Menurut mereka juga, gaya pembelajaran boleh dibahagikan kepada strategi kognitif, metakognitif dan afektif. Mike (2005) menyatakan manusia belajar dengan baik dalam pelbagai cara yang tersendiri. Setiap orang mempunyai gaya belajar yang disukai dan mereka belajar dengan baik menggunakan gaya pembelajaran tersebut. Apabila seseorang diberikan peluang untuk mengamalkan gaya pembelajaran tersendiri, maka hasilnya akan lebih optimum. Menurut pengkaji lepas yang lebih terdahulu, Pask (1976) menghuraikan gaya pembelajaran sebagai siri bertentangan dengan holistik atau serialist versus holist. Menurut beliau, pelajar yang mempunyai gaya pembelajaran bersiri lebih cenderung belajar dalam gaya berturutan manakala pelajar gaya keseluruhan pula lebih suka belajar dalam hierarki.

\section{Konsep Persekitaran Sekolah}

Persekitaran sekolah boleh ditakrifkan sebagai set ciri dalaman yang membezakan satu sekolah dengan sekolah lain dan mempemgaruhi tingkah laku ahli-ahlinya iaitu kakitangan dan pelajar Hoy dan Miskel (1987). Penyataan ini dikuatkan lagi Fraser (1986), beliau menyatakan bahawa faktor persekitaran sekolah adalah lebih luas dan tidak terhad kepada kelas. Selari dengan pandangan Jarzabkowski (2002), persekitaran sekolah merujuk kepada keseluruhan persekitaran, sumber dan aktiviti saling 
bersepadu secara langsung atau tidak yang memberi kesan kepada fungsi sekolah. Dari aspek yang lain, persekitaran sekolah merujuk kepada persekitaran fizikal dan iklim psikososial boleh menetapkan peringkat persepsi positif guru dan pelajar terhadap sekolah. Odogwu et al. (2011) menyatakan bahawa persekitaran sekolah sebagai persekitaran sosial, persekitaran afektif dan persekitaran akademik.

Sehubungan dengan ini Tableman (2004) telah mengenal pasti empat aspek persekitaran sekolah, iaitu persekitaran fizikal yang mesra dan kondusif untuk pembelajaran, persekitaran sosial yang menggalakkan komunikasi dan interaksi, persekitaran yang berkesan yang menggalakkan rasa kekitaan dan harga diri dan persekitaran akademik yang menggalakkan pembelajaran dan memenuhi diri. Persekitaran sekolah mempunyai pengaruh yang penting terhadap pembentukan tingkah laku, imej mental, aspirasi dan interaksi sosial bagi anggota-anggota di dalam sekolah (Abdullah Sani, 2007). Dapatan kajian oleh Mohd Redzauddin (2008), menunjukkan bahawa sekolah yang berpencapaian tinggi mempunyai tahap keceriaan dan keharmonian berbanding sekolah yang persekitarannya kurang ceria.

\section{Konsep Kecerdasan Emosi}

Menurut (Goleman, 1995), kecerdasan emosi adalah kebolehan untuk mengawal emosi dan emosi pihak lain, dapat mebezakan kebaikan dan dapat menggunakan maklumat untuk membantu fikiran serta tindakan seseorang. Kecerdasan emosi juga diertikan sebagai sejenis kecerdasan sosial yang bertanggungjawab untuk mengawal satu dan pelbagai emosi lain untuk mendiskriminasikan emosi tersebut dan menggunakan maklumat untuk mengawal pemikiran dan tindakan (Mayer \& Salovey,1993). Namun bagi Cary Cherniss (2001), beliau berpendapat bahawa kecerdasan emosi sebagai kemampuan melihat, menzahirkan dan menguruskan emosi diri sendiri dan orang lain.

\section{Teori dan Model}

\section{Teori Pembelajaran Kognitif}

Teori pembelajaran kognitif yang diasaskan oleh Bruner dan Simon pada tahun 1950. Seterusnya teori ini dipelopori dan dipopularkan oleh Rousseau, Ausubel, Piaget, Brunner, Gagne, Wertheimer, Wolfgang, Koffka, Kohlberg, Kohler, Dienes, Vygotsky, Graham, Palmer dan Lowenfeld (dalam Hussein, 1994). Dalam teori ini apabila seseorang pelajar mengalami proses pengajaran dan pembelajaran, mereka akan mengkod setiap pengalaman yang diterima dan menyimpannya di dalam ingatan jangka pendek mahupun ingatan jangka panjang. Menurut Kamarudin (2003) teori pembelajaran kognitif melibatkan proses mental yang mempunyai kesan terhadap tingkah laku manusia.

Menurut pengkaji lepas ini juga proses mental yang dimaksudkan tersebut berlaku dalam otak untuk membolehkan seseorang itu menguasai kemahiran berfikir dan proses ini berfokus kepada fenomena seperti kesediaan, persepsi, pengawalan motor, perhatian, ingatan, pembelajaran dan penaakulan. Perubahan tingkah laku digunakan sebagai petunjuk terhadap proses yang berlaku dalam fikiran pelajar. Ahli teori kognitif mengenal pasti bahawa pembelajaran melibatkan hubungan yang dijalin melalui amalan terus-menerus dan ulangan. Kognitif melibatkan proses penanggapan, pembinaan konsep, penaakulan, penilaian dan penyelesaian masalah. Pengukuhan adalah penting tetapi peranannya untuk memberi maklum balas seperti motivasi ditekankan (Ee, 1992b; Hussein, 1994; Baharuddin et al. 2002).

\section{Teori Kecerdasan Emosi Cadman \& Brewer (2001)}

Menurut Cadman \& Brewer (2001), terdapat lima ciri personaliti yang ditunjukkan oleh individu berkecerdasan emosi tinggi yang boleh dikategorikan kepada dua dimensi iaitu kompetensi personal dan kompetensi sosial. Dalam model ini Kompetensi Personal terdiri dari elemen kesedaran kendiri iaitu keupayaan mengenal pasti dan memahami perasaan, emosi, kekuatan, kelemahan, keperluan, dan dorongan dalam diri mereka sendiri terutama dari segi kesannya terhadap orang lain (Goleman, 1998). 
Kawalan Kendiri merujuk kepada keupayaan mengawal tekanan perasaan, menangani perubahan serta keupayaan untuk membuat inovasi. Elemen yang berikutnya adalah Motivasi Kendiri menjelaskan sekiranya individu yang mempunyai motivasi yang tinggi berani menghadapi cabaran, suka belajar, bertenaga untuk membuat sesuatu menjadi lebih baik, mengkaji pendekatan baru dalam kerja mereka dan berbangga dengan kerja yang telah dibuat dengan sempurna (Goleman, 1998).

Manakala Kompetensi Sosial pula terdiri dari elemen empati iaitu kebolehan untuk memahami dan mengenal pasti emosi orang lain dan kemahiran untuk melayan orang lain menurut emosi mereka. Elemen yang kedua dalam dimensi ini pula adalah Kemahiran Sosial iaitu kecekapan individu mengurus dan menangani perhubungan, membina rangkaian kerja dan kebolehan untuk mencari asas umum dan seterusnya membina perhubungan seperti pemujukan, pengurusan konflik dan kemahiran memimpin (Cadman \& Brewer, 2001).

\section{Model Kecerdasan Emosi Noriah (2005)}

Noriah (2005) telah menambah dimensi teori kecerdasan emosi yang telah dikemukakan oleh Goleman (2000). Antara komponen yang ditambah oleh Noriah adalah komponen kerohanian dan kematangan. Komponen kerohanian ini merujuk kepada perkara-perkara seperti keredaan, rasa tanggungjawab kepada Pencipta serta kebolehan menghayati nilai-nilai agama. Keredaan bermaksud kebolehan seseorang untuk menerima dengan hati yang rela peraturan-peraturan tertentu yang digariskan atau ditetapkan oleh agama masing-masing. Setiap peraturan-peraturan ini menjadi garis panduan yang harus diterima oleh seseorang dalam menjalani kehidupan.

Dimensi kedua yang ditambah oleh Noriah adalah kematangan. Kematangan ini merujuk kepada aspek usia, pengalaman dan pengetahuan seseorang serta kesannya terhadap kecerdasan emosi. Secara rasional usia seseorang akan mempengaruhi sikap seseorang itu dan biasanya akan menjadi lebih matang apabila usia bertambah. Sifat kematangan ini digambarkan sebagai kebolehan seseorang untuk mengawal tingkah laku apabila usia bertambah. Usia yang meningkat membantu seseorang untuk melakukan muhasabah diri untuk mengenal kelemahan dan kekuatan diri. Faktor pengalaman dapat digunakan untuk bertindak dengan lebih matang terhadap sesuatu permasalahan.

\section{Model Dunn dan Dunn (1992)}

Model pembelajaran Dunn telah diperkembangkan oleh Rita Dunn dan Kenneth Dunn. Menurut model ini, gaya pembelajaran seseorang individu banyak bergantung kepada lima rangsangan yang dianggap berperanan sebagai saluran interaksi dan tindak balas dengan persekitaran pembelajaran. Kelima-lima faktor ini, adalah gaya-gaya pembelajaran yang dimiliki oleh seseorang dalam melakukan aktiviti pembelajaran. Setiap individu mempunyai kecenderungan, keinginan, suasana pembelajaran, keperluan dan faktor fisiologi yang berbeza dalam diri masing-masing. Dalam model Dunn \& Dunn (1992), mengkategorikan ciri-ciri gaya pembelajaran dalam lima faktor atau ransangan iaitu faktor emosi, faktor persekitaran, faktor psikologi, faktor fizikal dan faktor sosial.

\section{Metod Kajian}

\section{Reka Bentuk Kajian}

Data daripada sumber primer adalah data yang digunakan dalam kajian ini iaitu maklum balas daripada soal selidik yang dijalankan. Data-data yang diperoleh dianalisis dan diuji dengan statistik deskriptif dan inferensi untuk menentukan sama ada terdapat perbezaan dan hubungan yang signifikan persepsi yang wujud dalam kalangan responden. Di samping itu juga, data sekunder banyak diperoleh daripada buku-buku rujukan, jurnal pendidikan, bahan ilmiah serta bahan-bahan capaian yang diakses daripada Internet untuk membantu pengkaji dalam penyelidikan ini. 


\section{Populasi dan Sampel Kajian}

Dalam kajian ini, populasi terdiri daripada 3765 orang pelajar dari lima buah sekolah menengah kebangsaan luar bandar dalam daerah Tawau, Sabah. Daripada populasi tersebut seramai 351 orang sampel djadikan sebagai responden kajian ini. Jumlah sampel ini adalah menepati cadangan yang dibuat oleh Krejcie dan Morgan (1970) berdasarkan jadual penentuan sampel yang telah dicadangkan. Menurut Krejcie dan Morgan (1970) menyatakan saiz poopulasi sebanyak 3500 hingga 4000 memerlukan 246 hingga 351 sampel. Oleh yang demikian pengkaji telah membuat keputusan untuk mengedarkan 400 borang soal selidik setelah mengambil kira bilangan keciciran yang mungkin berlaku semasa proses pemungutan soal selidik dibuat. Menurut Mohd Najib (2003), sampel adalah sumber untuk mendapatkan data kerana sampel sebenarnya mewakili keseluruhan populasi yang besar. Kesemua yang menjadi sampel kajian ini adalah dipilih secara pensampelan rawak mudah.

\section{Instrumen Kajian}

Instrumen kajian untuk kecerdasan emosi, pengkaji menggunakan item-item dari Cadman \& Brewer (2001) dengan menggabungkan idea model Mayer \& Salovey : Four Branch Model of Emotional Intelligence, Goleman (1998) dan Noriah (2005). Item gaya pembelajaran pula adalah item-item yang diubahsuai daripada gaya pembelajaran Dunn \& Dunn (1992) dan persekitaran sekolah pula dari Elementary and Middle School Climate Survey yang dibangunkan oleh Haynes, Emmons, \& Comer (1993) dan School Level of Environment Questionnaire (SLEQ) yang dibangunkan oleh Rentoul dan Fraser (1983). Pengkaji mengadaptasikan item-item yang sesuai dengan faktor yang hendak dikaji dalam kajian ini. Item-item yang dipilih mencakupi pelbagai aspek yang berkaitan dengan kecerdasan emos, gaya pembelajaran dan persekitaran sekolah. Pengkaji mengubahsuai bentuk item untuk disesuaikan dengan konteks kajian ini.

\section{Dapatan Kajian}

Bahagian ini menjelaskan hasil analisis data dan menyatakan dapatan kajian mengikut urutan soalan kajian. Pengkaji menunjukkan hasil kajian dalam bentuk jadual dan disertakan dengan penjelasan. Pengkaji turut menyatakan sama ada hipotesis yang dibina pada awal kajian diterima atau ditolak serta memberikan tafsirannya.

Jadual 1: Hubungan Gaya Pembelajaran dengan Kecerdasan Emosi

\begin{tabular}{lll}
\hline Pemboleh Ubah & & Kecerdasan Emosi \\
\hline Gaya Pembelajaran & $\mathrm{r}$ & .453 \\
& $\mathrm{P}$ & .001 \\
& $\mathrm{~N}$ & 361 \\
\hline $\mathrm{P}<.05$ & &
\end{tabular}

Berdasarkan Jadual 1, dapatan kajian menunjukkan terdapat hubungan yang signifikan antara gaya pembelajaran murid dengan kecerdasan emosi murid $\mathrm{r}=.453, \mathrm{p}<.05$. Berdasarkan jadual tersebut, kekuatan hubungan adalah sederhana kuat dan positif. Oleh itu hipotesis nul yang menyatakan tidak terdapat hubungan yang signifikan gaya pembelajaran murid dengan kecerdasan emosi adalah ditolak.

Jadual 2: Hubungan Persekitaran Sekolah dengan Kecerdasan Emosi

\begin{tabular}{lll}
\hline Pemboleh Ubah & & Kecerdasan Emosi \\
\hline Persekitaran Sekolah & $\mathrm{r}$ & .528 \\
& $\mathrm{P}$ & .001 \\
& $\mathrm{~N}$ & 361 \\
\hline
\end{tabular}


Berdasarkan Jadual 2 di atas, dapatan kajian menunjukkan terdapat hubungan yang signifikan antara persekitaran sekolah murid dengan kecerdasan emosi murid $\mathrm{r}=.528, \mathrm{p}<.05$. Berdasarkan Jadual 2.0, kekuatan hubungan adalah tinggi dan positif. Oleh itu hipotesis nul yang menyatakan tidak terdapat hubungan yang signifikan persekitaran sekolah murid dengan kecerdasan emosi adalah ditolak.

\section{Rumusan dan Cadangan}

Penyelidikan ini melihat sejauh mana hubungan pemboleh ubah bersandar iaitu gaya pembelajaran dan persekitaran sekolah dengan pemboleh ubah tidak bersandar iaitu kecerdasan emosi murid sekolah menengah luar bandar daerah Tawau, Sabah. Berdasarkan kepada hasil kajian yang dijalankan menunjukkan terdapatnya hubungan di antara gaya pembelajaran dan persekitaran sekolah dengan kecerdasan emosi. Dapatan kolerasi adalah sederhana kuat dan kuat yang menunjukkan bahawa gaya pembelajaran dan persekitaran sekolah mempunyai hubungan dengan kecerdasan emosi murid sekolah menengah. Sehubungan dengan ini implikasi kajian dan cadangan sahaja tidak mencukupi andainya pelbagai pihak tidak mengambil peduli akan kepentingan kecerdasan emosi dalam kalangan murid. Adalah diharapkan hasil kajian ini juga dapat memberi cadangan yang bernilai kepada pihak tertentu yang terlibat secara langsung dan tidak langsung dalam bidang pendidikan. Oleh hal yang demikian kajian ini mengesyorkan bahawa program kesedaran kepada ibu bapa dan guru-guru agar mampu melihat kecerdasan emosi murid serta kepentingannya dalam melahirkan murid yang seimbang dari segi intelek dan emosi.

\section{Kesimpulan}

Penyelidik berharap inti pati dapatan kajian ini dapat membantu para guru, pentadbir dan pihak berkepentingan untuk mengambil kira dan melihat gaya pembelajaran yang sesuai untuk murid dan persekitaran sekolah murid serta hubungannya dengan kecerdasan emosi murid sekolah menengah luar bandar. Dengan mengetahui tahap kecerdasan emosi, gaya pembelajaran dan persekitaran sekolah berdasarkan item membolehkan pengetua menjadi pemimpin sekolah yang mempunyai gaya yang sesuai dengan situasi sekolah dan peribadi guru ke arah penambahbaikan sekolah. Selain itu dengan mengetahui semua maklumat di atas akan dapat memberi input kepada guru serta ibu bapa bahawa kecerdasan emosi adalah sesuatu yang sama pentingnya dengan kecerdasan intelek atau pencapaian pelajar di sekolah.

\section{Rujukan}

Abdul Rahman an-Nahlawi. (1995). Membina sekolah berkesan. Aplikasi dasar. Seminar Sekolah Efektif anjuran Kementerian Pendidikan pada 13-14 Julai 1995 di Institut Aminudin Baki.

Abdullah Sani bin Yahya. (1997). Mengurus Sekolah. Kuala Lumpur: PTS Profesional Publishing Sdn. Bhd.

Ahmad Zabidi Abdul Razak. (2006). Ciri Iklim Sekolah Berkesan: Implikasinya Terhadap Motivasi Pembelajaran. Jurnal Pendidikan. 31: 3-19.

Baharuddin Aris, Rio Sumarni Shariffudin \& Manimegalai Subramaniam. (2002). Reka Bentuk Perisian Multimedia. Skudai: Penerbit Universiti Teknologi Malaysia.

Cadman, C., \& Brewer, J.F. (2001). Emotional intelligence: a vital prerequisite for recruitment in nursing. Journal of nursing management, 9 6, 321-4.

Cherniss, Cary \& Goleman, Daniel. (2001). The Emotionally Intelligent Workplace: How to Select for, Measure, and Improve Emotional Intelligence in Individuals, Groups, and Organizations.

Clark-Thayer, S. (1987). The Relationship of the Knowledge of Student-Perceived Learning Styles Preference and the Study of Habits and Attitude to Achievement of College freshmen in an Urban University. Doctoral dissertation. Boston University, 1987. Dissertation Abstracts International, 48, 872A.

Daniel Goleman. (1995). Emotional Intelligence: Why it can Matter more than IQ. New York: Bantam Books 
Daniel Goleman. (1998). Working with Emotional Intelligence. New York: Bantam Books.

Dunn, R., \& Dunn, K. (1992). Teaching secondary students through their individual learning styles. Boston: Allyn \& Bacon.

Ee Ah Meng. 1992. Psikologi Perkembangan. Aplikasi dalam Bilik Darjah. Edisi Kedua. Kuala Lumpur: Fajar Bakti Sdn. Bhd.

Fraser, B.J. (1986). Classroom Environment. Croom Helm, London

Freiberg, H.J. (1998). Measuring School Climate: let me count the ways. Educational Leadership. 56(1):22-26.

Halpin, A. W. \& Croft D. B. (1963). The Organizational Climate of School. Chicago: Midwest Administration Centre, University of Chicago.

Hoy, W.K. \& Tarter, C.J. (1997). The road to open and healthy schools: A handbook for change (Elementary ed.). Thousand Oaks, CA: Corwin Press.

Hussein Mahmood. (1994). Teori-Teori Pengajaran dan Implikasi. Petaling Jaya: Prints Press.

Ibrahim Mamat. (1993). Kepimpinan sekolah. Teori untuk praktis. Kuala Lumpur. Kumpulan Budiman Sdn. Bhd.

Jarzabkowski, L.M. (2002). The social dimension of teacher collegiality. Journal of Educational Enquiry 3(2): 1-20.

Kamarudin Hj. Husin. (2003). Kemahiran Berfikir dan Berkomunikasi. Kuala Lumpur: Percetakan Sentosa (K.L) Sdn. Bhd

Krejcie, R.V. \& Morgan, D.W. (1970). Determining Sample Size for Research Activities. Educational and Psychological Measurement.

Mahmood Nazar Mohamed (1992). Pengantar Psikologi: Satu Pengenalan Asas Kepada Jiwa dan Tingkah Laku Manusia. Kuala Lumpur. Dewan Bahasa dan Pustaka.

Mayer, J. D., \& Salovey, P. (1993). The intelligence of emotional intelligence. Intelligence, 17(4), 433-442. https://doi.org/10.1016/0160-2896(93)90010-3

Mayer, J. D. dan Cobb, C. D. (2000). Educational policy on emotional intelligence: does it make sense? Educational psychology review 12:163-183.

Mike Hughes. 2005. Strategies for Closing the Leraning Gap. Cornwell: Network Education Press Ltd.

Mohamad Najib Ghafar. (2003). Kaedah Penyelidikan. Johor. Universiti Teknologi Malaysia.

Mohd Redzauddin bin Ismail. (2008). Hubungan Reka bentuk Landskap Sekolah dengan Pencapaian Prestasi Akademik Pelajar Sekolah Menengah di Besut, Terengganu. Selangor: Universiti Putera Malaysia.

Ng Sook Chin. (2005). Relationship Between Learning Styles and Understanding of Selected Concepts Among Pre-University Science Students. Tesis Sarjana. Universiti Malaya. Kuala Lumpur.

Noriah Mohd Ishak, Siti Rahayah Ariffin \& Zuria Mahmud. (2005). Inventori Kecerdasan EmosiDewasa (IKEM-D). Universiti Kebangsaan Malaysia, Bangi.

Odogwu, H., Adeyemo, S., Jimoh, J. and Yewonde, R. (2011). Science, mathematics and technology teachers' perception of school environment: Gender differences. Multicultural Education \& Technology Journal, 5(4), 274-287. https://doi.org/10.1108/17504971111185108

Pask. G. (1976). Styles and Strategies of Learning. British Journal of Educational Psychology. 46:128-148.

Rita Dunn. (1984). Learning style: State of the science, Theory Into Practice, 23:1, 1019, DOI: $10.1080 / 00405848409543084$

Sureshkumar A/L Kesavelu. (2005). Hubungan diantara Gaya Pembelajaran dengan Pencapaian Akademik Pelajar sarjana Muda Teknologi serta Pendidikan di UTM dalam Mata Pelajaran Teknologi Pengeluaran Asas. Tesis Sarjana Muda. Universiti Teknologi Malaysia, Johor.

Tableman, B. (2004). School climate and learning. Best practice briefs, Michigan State University: Michigan

Vermunt, J.D.H.M. and Van Rijswijk, F.A.W.M. (1988). An Analysis and Development of Students. Skill in Self-regulated learning Higher education. 17:647-682.

Zainudin bin Abu Bakar \& Md. Saharudin bin Kasri. (2009). Gaya Pembelajaran dalam Kalangan Pelajar Tingkatan Dua Sekolah Menengah Kebangsaan Bukit Gambir Dalam Mata Pelajaran Kemahiran Hidup. Fakulti Pendidikan Universiti Teknologi Malaysia. 